\title{
Green Synthesis of Gold Nanoparticles with Self-Sustained Natural Rubber Membranes
}

\author{
Flávio C. Cabrera, ${ }^{1}$ Haider Mohan, ${ }^{2}$ Renivaldo J. dos Santos, ${ }^{1}$ Deuber L. S. Agostini, ${ }^{1}$ \\ Ricardo F. Aroca, ${ }^{2}$ Miguel A. Rodríguez-Pérez, ${ }^{3}$ and Aldo E. Job ${ }^{1}$ \\ ${ }^{1}$ Faculdade de Ciências e Tecnologia, UNESP Universidade Estadual Paulista, CP 467, 19060-080 Presidente Prudente, SP, Brazil \\ ${ }^{2}$ Materials and Surface Science Group, University of Windsor, Windsor, On, Canada N9B 3P4 \\ ${ }^{3}$ CellMat Laboratory, Condensed Matter Physics Department, University of Valladolid, 47011 Valladolid, Spain
}

Correspondence should be addressed to Aldo E. Job; job@fct.unesp.br

Received 26 June 2013; Accepted 17 August 2013

Academic Editor: Hongchen Chen Gu

Copyright (C) 2013 Flávio C. Cabrera et al. This is an open access article distributed under the Creative Commons Attribution License, which permits unrestricted use, distribution, and reproduction in any medium, provided the original work is properly cited.

\begin{abstract}
Green chemistry is an innovative way to approach the synthesis of metallic nanostructures employing eco-friendly substances (natural compounds) acting as reducing agents. Usually, slow kinetics are expected due to, use of microbiological materials. In this report we study composites of natural rubber (NR) membranes fabricated using latex from Hevea brasiliensis trees (RRIM 600) that works as reducing agent for the synthesis of gold nanoparticles. A straight and clean method is presented, to produce gold nanoparticles (AuNP) in a flexible substrate or in solution, without the use of chemical reducing reagents, and at the same time providing good size's homogeneity, reproducibility, and stability of the composites.
\end{abstract}

\section{Introduction}

The synthesis of noble metals nanostructures for plasmonic applications is a very active field of research $[1,2]$. One of the objectives is to develop chemical routes of controlling the homogeneity of nanoparticles formation with desired size $[3,4]$ and shape [5]. The fabrication of nanostructures follows the demand for specific optical properties [6] allowing potential applications [7]. In particular, we are interested in plasmon enhanced scattering (SERS and SERRS) and plasmon enhanced fluorescence (SEF) $[8,9]$ applications.

In general, the synthesis of gold nanoparticles is commonly carried out using colloidal chemistry. The latter involves the use of chemicals (reducing/stabilizing reagents), among which are sodium citrate, sodium borohydrate, ascorbic acid, fulvic acid, and so forth [10]. There is a wide range of methods that may be employed to fabricate gold nanostructures such as vacuum evaporation [11] and electrochemical techniques [12, 13]. In addition, arrays of gold nanoparticles can be fabricated using the Langmuir-Blodgett (LB) technique, nanolithography, and layer-by-layer deposition [14].
Currently, the green chemistry, using eco-friendly substances (natural compounds) as reducing/stabilizing reagents, opens a broad range of materials like extracts from different leaves [15, 16], fruits [17, 18], seeds [19], and flowers $[20,21]$ as well as microbiological compounds from algae bacteria [22], and fungi [23] to develop gold nanoparticle synthesis. These materials minimize the use of chemical compounds and the generation of waste attributed to reagents or solvents included in the chemical synthesis. In some of these cases, the researcher needs a specific knowledge regarding the use of microbiological materials or the extraction of natural products. The natural rubber used here provides a viable alternative: it is accessible and inexpensive natural product. It can now be included in the list of organic compounds used to generate green synthesis, that is, for reduction and stabilization of metallic nanostructures.

Previous work showed that both latex and seed extract from Jatropha curcas [24,25] and latex from Hevea brasiliensis [26] are used in solution for synthesis of silver nanoparticles. In addition, cream fraction of latex from ammoniated NR latex and deproteinized natural rubber latex is also used 
to synthesize silver nanoparticles [27]. Similarly, epoxidized natural rubber (ENR) is used as polymeric stabilizer of both platinum and gold nanoparticles, after being dissolved in toluene and mixed with colloids prepared by sodium borohydrate [28].

The characterization of the constituents of latex has been previously reported $[29,30]$. The studies revealed three phases: rubber solid or latex particles, serum, and bottom phase. The first phase is attributed to the monomers isoprene, the main constituent of natural rubber chain that constitute of near to $60-40 \%$ dry rubber. The composition of serum phase is approximately 1.0 to $1.8 \%$ protein, 1.0 to $1.2 \%$ carbohydrate, 0.4 to $1.1 \%$ neutral lipids, 0.4 to $0.5 \%$ polar lipids, 0.4 to $0.6 \%$ inorganic lipids, $0.4 \%$ amino acids, amines among others, and 50 to $60 \%$ water $[29,31]$. Finally, the bottom fraction contains compounds responsible for the connection between plant and soil, containing a high portion of the monomers with metal ions.

Natural rubber has been the object of research involving a wide range of applications, for example, the fabrication of composites and synthesis of new material [32-34]; it also has been evaluated for its medicinal properties such as induction of angiogenesis and neoformation issue [35]. The composite NR/AuNPs maintains the elastomeric mechanical properties (elasticity and flexibility) increasing the rupture tensile; both materials are biocompatible. Furthermore, gold nanoparticles could work as enzyme support/catalysis or can be used to fabricate sensor devices. Natural rubber membranes with incorporation of gold nanoparticles produced flexible membranes that may be used as substrate for ultrasensitive detection and chemical analysis in plasmon enhanced Raman spectroscopy [36]. These composites membranes can act as a growth inhibitor of Leishmania brasiliensis promastigotes in vitro [37].

In this study, we propose a new fast clean green chemistry method for synthesis of eco-friendly and nontoxic gold nanoparticles dispersed in solution, as well as the formation of a flexible substrate of natural rubber with gold nanoparticles, a polymeric biocompatible nanocomposite matrix. The NR membranes are produced by casting the annealed latex (without the traditional vulcanization agent sulfur). The AuNPs were formed at the NR membrane surface through the reduction of gold (III) from $\mathrm{AuCl}_{3}$, in aqueous solution kept at $80^{\circ} \mathrm{C}$ for different reaction times, which leads to diverse NR/Au composites.

\section{Experimental}

2.1. Natural Rubber Membranes Preparation. Natural rubber (NR) forming self-sustainable membranes are prepared using latex collected from different rubber trees of the Hevea brasiliensis (RRIM 600 clone) [38] in an experimental farm in Indiana city, in the region of Presidente Prudente, Sao Paulo state, Brazil. The sample was stabilized with $2 \%$ of ammonium hydroxide. The NR cis-1,4-polyisoprene has a glass transition at $-67^{\circ} \mathrm{C}$. NR membranes of $0.5 \mathrm{~mm}$ thickness $(40-60 \%$ of dry rubber) were fabricated by casting latex on glass and annealing for 10 hours at $65^{\circ} \mathrm{C}, 80^{\circ} \mathrm{C}$, and $120^{\circ} \mathrm{C}$.
2.2. Synthesis of Gold Nanoparticles. The formation of AuNPs was achieved by direct reaction of the NR membrane in a solution of gold chloride $\left(3.1 \times 10^{-4} \mathrm{M}\right)$ chosen according to colloid preparation methods by chemical reduction [10]. The gold (III) chloride $99.99 \%\left(\mathrm{AuCl}_{3}\right)$ was purchased from Aldrich. The synthesis was carried out at $80^{\circ} \mathrm{C}$ for immersion periods of $6,9,15,30,60$, and 120 minutes.

2.3. Characterization. UV-Vis plasmon absorption was recorded using a Varian spectrophotometer, model Cary 50, with a scan range from 190 to $1100 \mathrm{~nm}$. The analysis TG, Netzsch model 209, was used near $15.0 \mathrm{mg}$ mass, deposited in an alumina crucible, and pure nitrogen gas $\left(\mathrm{N}_{2}\right)$ was used as carrier gas $(15 \mathrm{~mL} / \mathrm{min})$. The heating rate was $10^{\circ} \mathrm{C} / \mathrm{min}$, and the temperature range was between 25 and $600^{\circ} \mathrm{C}$. The spectra TG coupled to FT-IR spectroscopy of evaporated components were recorded on a Vector 22 spectrometer from Bruker, with wavenumber that covers the range between 600 and $4000 \mathrm{~cm}^{-1}$ with $4 \mathrm{~cm}^{-1}$ spectral resolution for detector MCT. SEM measurements from solutions of gold nanoparticles were done using a FEI Quanta 200 FEG microscope with a field emission gun (filament), equipped with an everhart-thornley secondary electron detector, and a solid state backscatter detector. SEM analysis was done at the Great Lakes Institute for Environmental Research in Windsor-Canada. The SEM substrate used is HOPG (highly ordered pyrolytic graphite) disk.

\section{Results}

3.1. Reaction Kinetics of Gold Nanoparticles. First, gold nanoparticles from on the surface of membranes (reducing agent) prepared at $65^{\circ} \mathrm{C}$ (thermal treatment) that are characterized by UV-Vis spectroscopy, showing an absorbance band around $560 \mathrm{~nm}$ that can be assigned to the localized surface plasmon resonance (LSPR) of gold nanoparticles. The band intensity increased with increasing reduction time. Second, the nanoparticle fabrication is extended to include membranes prepared at different temperatures in the thermal treatment $\left(65,80\right.$, and $\left.120^{\circ} \mathrm{C}\right)$ presented in Table 1.

The plasmon absorption bands of AuNPs show an exponential increase in intensity with the reaction (immersion) time of the membrane in the gold chloride solution, which is seen with good reproducibility until $30 \mathrm{~min}$. The reaction kinetics were previously studied [36, 39].

Studies carried out with reaction times of 120 minutes lead to saturation in plasmon absorption intensity due to nanoparticle aggregation.

Furthermore, the higher the temperature of thermal treatment of the natural rubber membranes (reducing agent), the stronger the absorbance intensity of the LSPR band, which is attributed to larger amount of nanoparticles, formed in the natural rubber matrix.

Analysis of the $\mathrm{pH}$ changes in the solution used for synthesis of nanoparticles during the reduction process is shown in Figure 1.

A nearly exponential behavior can be seen, where the $\mathrm{pH}$ decreases with increasing reaction time, attributed to gold 
TABLE 1: Plasmon resonance absorption results at $560 \mathrm{~nm}$ for NR/Au membranes prepared with different reduction time. Synthesis using natural rubber membranes prepared at 65,80 , and $120^{\circ} \mathrm{C}$.

\begin{tabular}{lcccccc}
\hline \multirow{2}{*}{ Reduction time } & \multicolumn{2}{c}{ NR membranes prepared at $65^{\circ} \mathrm{C}$} & \multicolumn{2}{c}{ NR membranes prepared at $80^{\circ} \mathrm{C}$} & \multicolumn{2}{c}{ NR membranes prepared at $120^{\circ} \mathrm{C}$} \\
& Average abs. & Standard deviation & Average abs. & Standard deviation & Average abs. & Standard deviation \\
\hline $6 \mathrm{~min}$ & 0.0691 & 0.0162 & 0.0911 & 0.0192 & 0.0927 & 0.0183 \\
$9 \mathrm{~min}$ & 0.0957 & 0.0199 & 0.1586 & 0.0179 & 0.1641 & 0.0232 \\
$15 \mathrm{~min}$ & 0.1567 & 0.0174 & 0.3101 & 0.1646 & 0.3205 & 0.0332 \\
$30 \mathrm{~min}$ & 0.4477 & 0.0158 & 0.8631 & 0.1715 & 0.8023 & 0.0699 \\
$60 \mathrm{~min}$ & 1.2073 & 0.1419 & 2.2393 & 0.0883 & 2.5307 & 0.3379 \\
$120 \mathrm{~min}$ & 4.2756 & 3.1723 & 5.3294 & 3.0143 & 5.4489 & 2.6496 \\
\hline
\end{tabular}

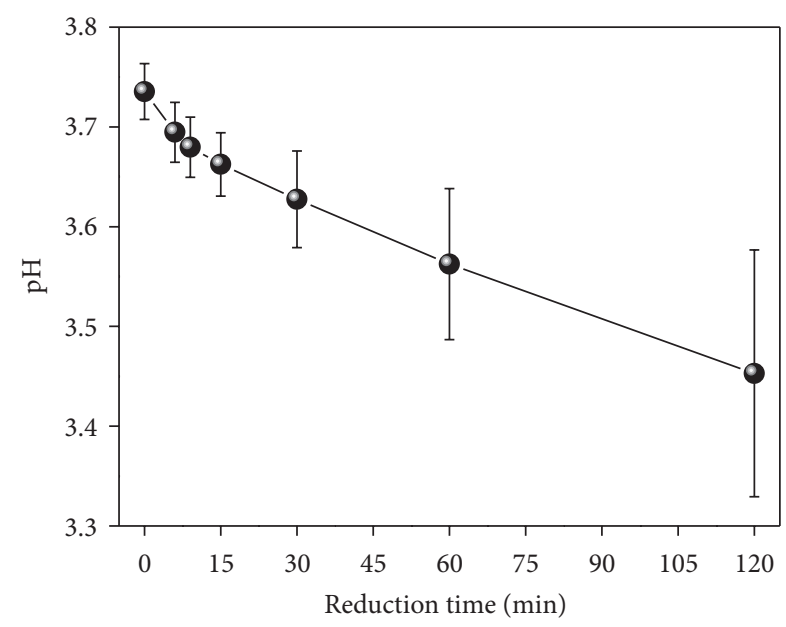

FIGURE 1: $\mathrm{pH}$ variation in the solution used for synthesis of NR/Au membranes at different reduction times, using natural rubber prepared at $65^{\circ} \mathrm{C}$ as reducing agent.

reduction and formation of ions $\mathrm{H}^{+}$according to the following reaction:

$$
\mathrm{AuCl}_{3}+\mathrm{H}_{2} \mathrm{O} \longrightarrow\left(\mathrm{AuCl}_{3}\right) \mathrm{OH}^{-}+\mathrm{H}^{+}
$$

The kinetic growth of the gold nanoparticles using natural rubber membranes prepared at $65^{\circ} \mathrm{C}$ was reported [39] showing that increasing the reduction time raises the amount of nanoparticles deposited on natural rubber surface as well as the nanoparticle's size. Here, the natural rubber prepared at different temperatures (annealed at 65,80 , and $120^{\circ} \mathrm{C}$ ) and 15 minutes of reduction reaction time and imaged using SEM microscopy are presented in Figure 2 with micrometer magnification (top) and nanometric resolution (bottom), where nanostructures of ca. $50 \mathrm{~nm}$ diameter are clearly seen in the NR/Au membranes.

Increasing the annealing temperature in the preparation of the natural rubber membranes improves the formation of nanoparticles synthesized on the surface of the natural rubber membranes. That latter may be attributed to the higher density of both organics and, particularly, organic acids generated during the degradation of proteins of the protein phase of the natural rubber membranes. Membranes annealed at $65^{\circ} \mathrm{C}$ show a distribution of shapes close to that found in colloidal solutions. However, membranes of natural rubber prepared at 80 and $120^{\circ} \mathrm{C}$ show good homogeneity of nanoparticle aggregates on the surface (see top of Figure 2).

3.2. Evaluation of the Compounds Released from Natural Rubber into the Solution. The compounds released from natural rubber in solution were studied by insertion of about $2 \mathrm{~g}$ of natural rubber inside of $50 \mathrm{~mL}$ of water, kept at $80^{\circ} \mathrm{C}$, for 120 minutes. The UV-Vis spectrum of the solution is provided in the supporting information (see Figure S1 in Supplementry Material available online at http://dx.doi.org/10.1155/2013/710902). Two absorption bands observed at 217 and $264 \mathrm{~nm}$ can be assigned to aromatic compounds. To identify these compounds, the NR $+\mathrm{H}_{2} \mathrm{O}$ solution was lyophilised, and the solid compound was analysed by TG/FT-IR (Figure 3). The assignment of the observed vibrational bands is given in the supporting information Table S1 [29, 31, 40, 41].

It is possible to identify the functional groups from esters (1040-1080, 1596, and $1755 \mathrm{~cm}^{-1}$ ) and also amides (characteristic to link between amines and aromatic carboxylic acids) $\left(1620\right.$ and $3265 \mathrm{~cm}^{-1}$ ); both are compound types (nonrubber) that can participate as reducing agent in synthesis process of gold nanoparticles. Peaks (928, 972, 1001, 1336, 1379, 2877 , and $2965 \mathrm{~cm}^{-1}$ ), found in TG/FT-IR analysis, can be attributed to $\mathrm{CH}$ - and $\mathrm{CH}_{2}$ - groups mainly found on isoprene structure, the main constituent of natural rubber chain. The released of amides from polymeric chain can be attributed to polymer's hydrolysis in water $[42,43]$ and also to $\alpha$-terminal groups compounds of mono- or diphosphate linked with phospholipids [44].

TG/FT-IR analysis of latex phase constituents separated by centrifugation is shown in Figure 4 .

Characteristic vibrational bands at $2933,1456,1388$, and $887 \mathrm{~cm}^{-1}$ seen in Figure 4(b) correspond to the rubber phase and bottom fraction, containing mainly isoprene. In fact, they are not seen in the analysis of the serum phase or substances released by natural rubber membrane in water. In addition, there are obvious similarities between components released into solution by natural rubber and those in the serum phase (Figure 4(a)), in particular, compounds containing ester $\left(1534 \mathrm{~cm}^{-1}\right)$, amides $\left(1672 \mathrm{~cm}^{-1}\right)$, and carboxylic acids $\left(1737 \mathrm{~cm}^{-1}\right)$. It is important to point out that the rubber phase has a single region of degradation that appears around $361^{\circ} \mathrm{C}$ (Figure 4(b)). Figure 4(a) shows that at a temperature of $268^{\circ} \mathrm{C}$, there are similar vibrational bands 

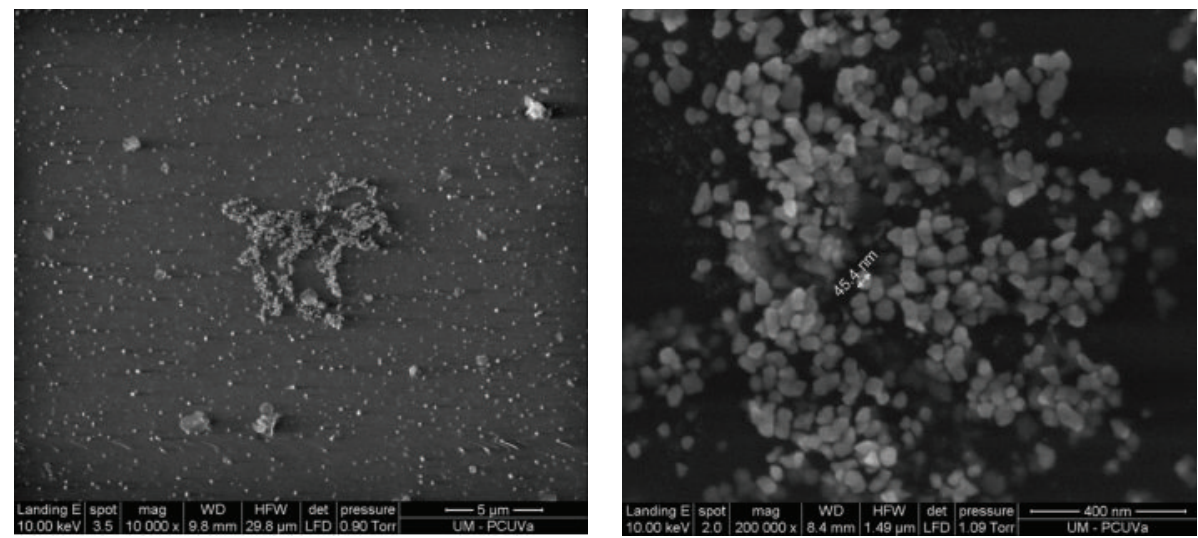

(a)
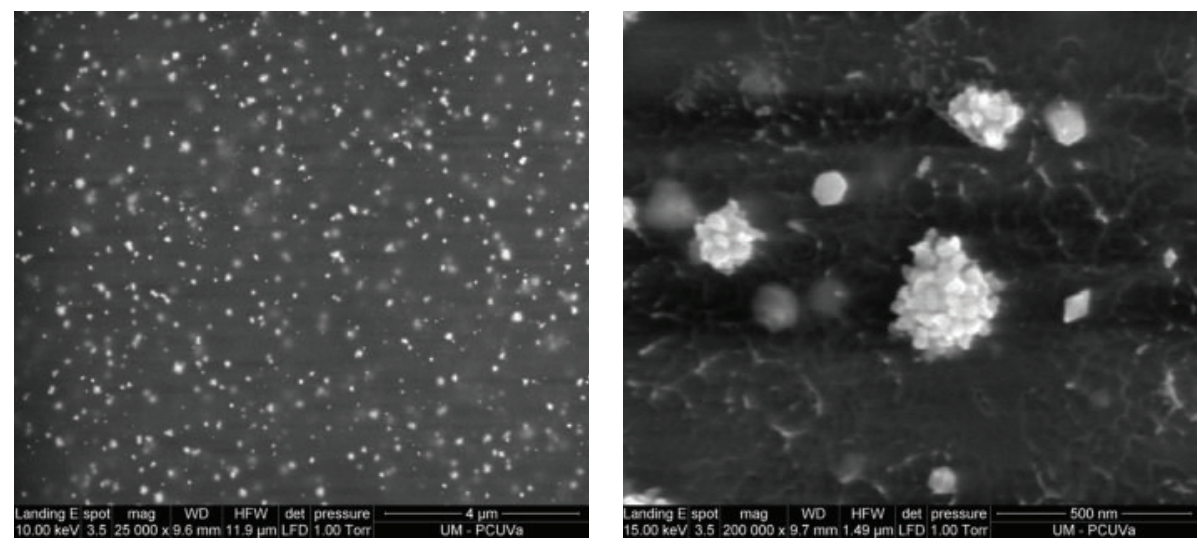

(b)
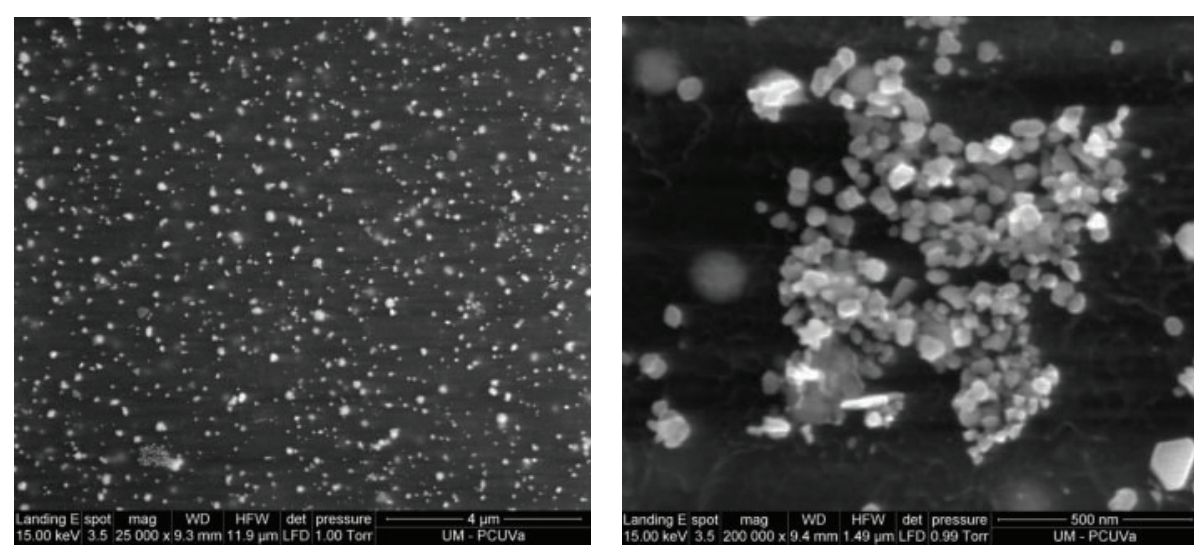

(c)

FIGURE 2: SEM images from NR/Au membranes prepared with 15 min reduction time, using natural rubber membranes annealed at (a) $65^{\circ} \mathrm{C}$ (b) $80^{\circ} \mathrm{C}$, and (c) $120^{\circ} \mathrm{C}$ (thermal treatment casting).

in the spectra of the serum phase, the bottom fraction, and the components released in water by NR membranes, which is attributed to protein constituents (1741 and $1517 \mathrm{~cm}^{-1}$ ) and constituents relative to isoprene at 1058, 967, and $928 \mathrm{~cm}^{-1}$. The serum phase provides good agreement with the components released into solution, since characteristic vibrational bands at 2961, 1461, and $1394 \mathrm{~cm}^{-1}$ of the natural rubber are not observed. It is concluded that the solid membrane from natural rubber latex, prepared through thermal treatment, releases constituents weakly bound to the main chain of the polymer (isoprene monomer). These constituents are mainly from the latex serum phase and become the reagents responsible for the reduction of gold to form nanoparticles in solution.

To complete the chemical analysis and a study of the vibrational properties of $\mathrm{NR}$ and NR/Au membranes has 


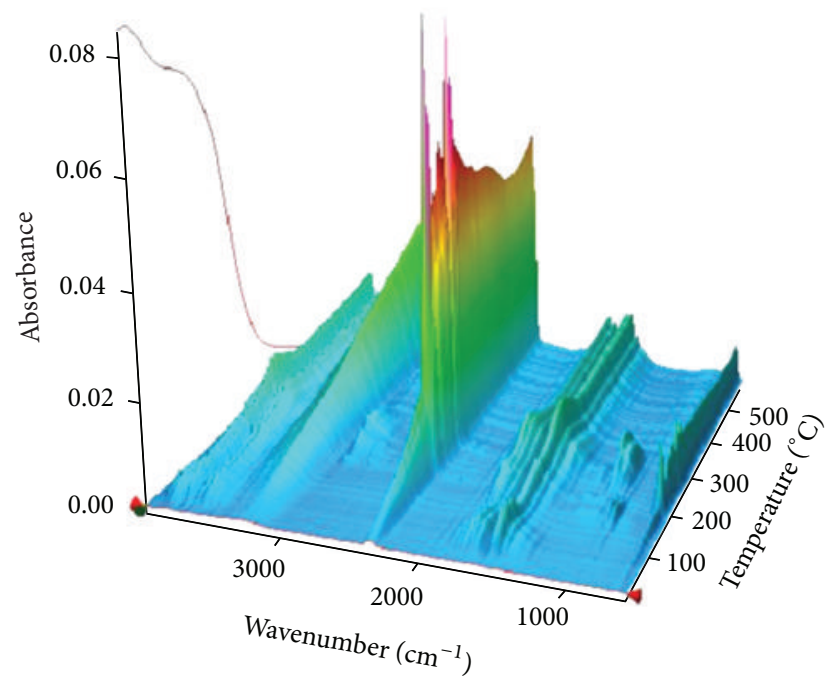

(a)

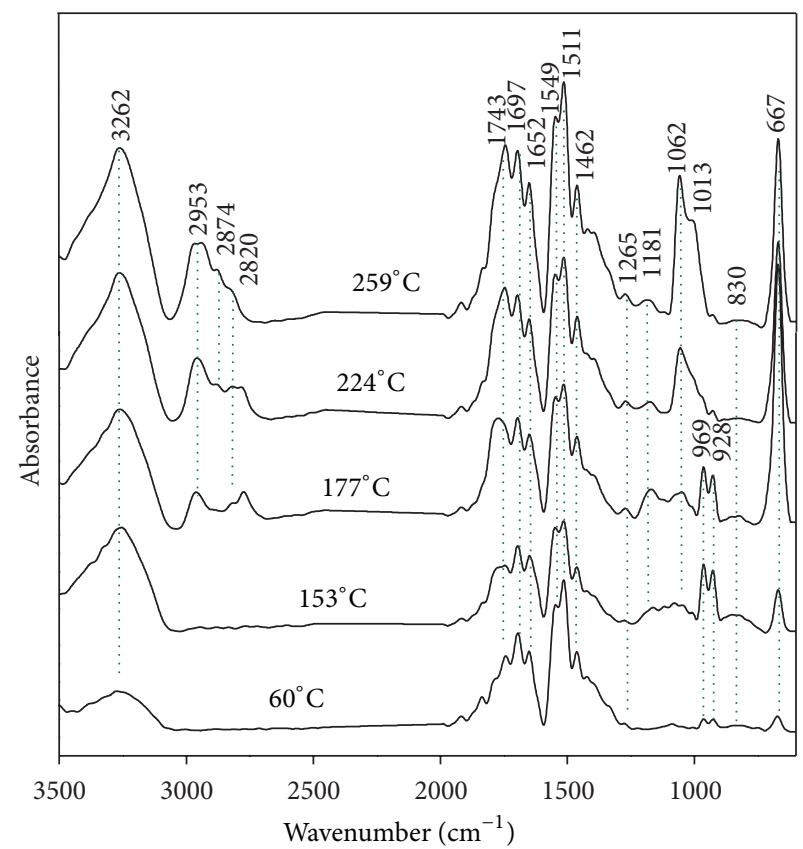

(b)

Figure 3: (a) 3D TG/FT-IR image from lyophilised solution of $\mathrm{H}_{2} \mathrm{O}$ where the NR membrane (2 g) was immersed for 2 hours at $80^{\circ} \mathrm{C}$; (b) spectra extracted from 3D TG/FT-IR image at $60,153,177,224$, and $259^{\circ} \mathrm{C}$ obtained for $\mathrm{NR}+\mathrm{H}_{2} \mathrm{O}$ (lyophilised solution) prepared under the same conditions.

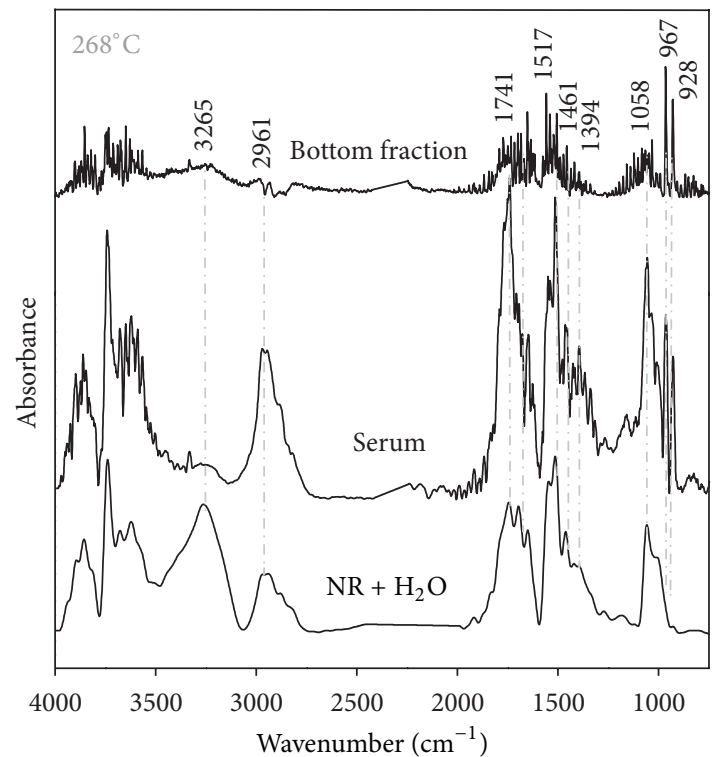

(a)

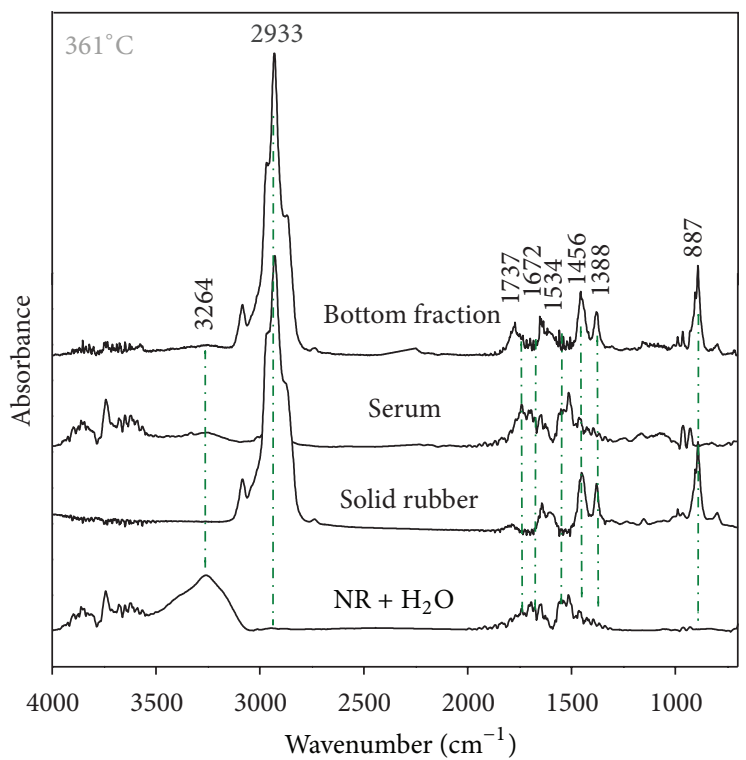

(b)

FIgure 4: Spectra extracted from 3D TG/FT-IR images at (a) $268^{\circ} \mathrm{C}$ and (b) $361^{\circ} \mathrm{C}$. Results obtained analysing the lyophilized solution in $\mathrm{H}_{2} \mathrm{O}$. Also, $2.0 \mathrm{~g}$ of NR membrane was immersed for 2 hours at $80^{\circ} \mathrm{C}$. Comparison with different latex phases (bottom and serum phase) after being lyophilised.

been attempted. By thermogravimetric analysis coupled with FT-IR spectroscopy, the components evaporated of the samples during thermal treatment between room temperature and $600^{\circ} \mathrm{C}$ are analyzed qualitatively. Figure 5 shows the graph TG/FT-IR of natural rubber membranes showing that all membranes presented similar behavior.
In the TG curves, there is a first step of $5 \%$ loss in mass between 100 and $250^{\circ} \mathrm{C}$ attributed to the release of water molecules and processes of cross-linking and scission of polymer chains, and the main step is assigned to the degradation process starting near $250^{\circ} \mathrm{C}$ and ends around $400^{\circ} \mathrm{C}$, showing a loss of $84 \%$ mass, a characteristic of isoprene 


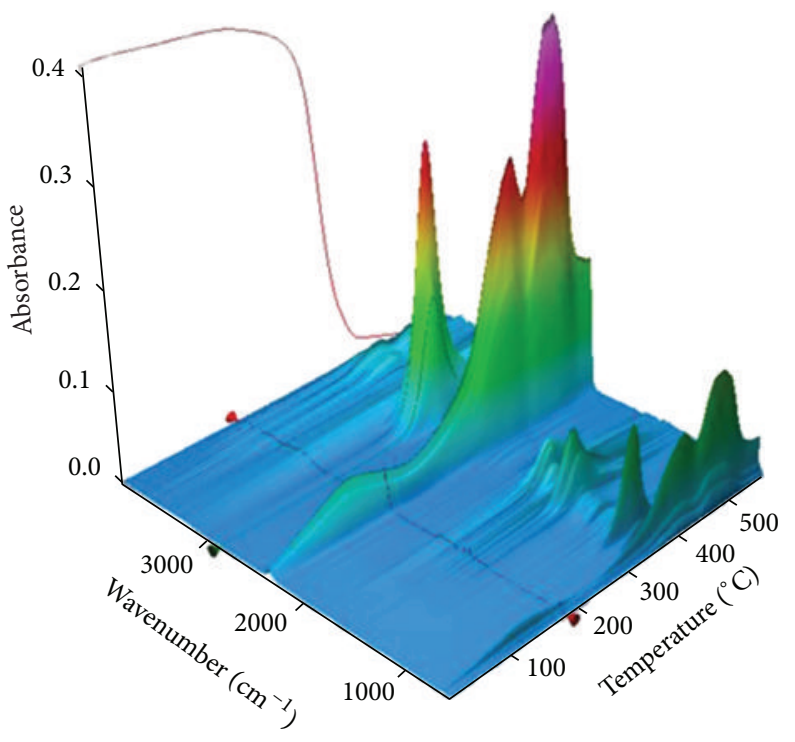

(a)

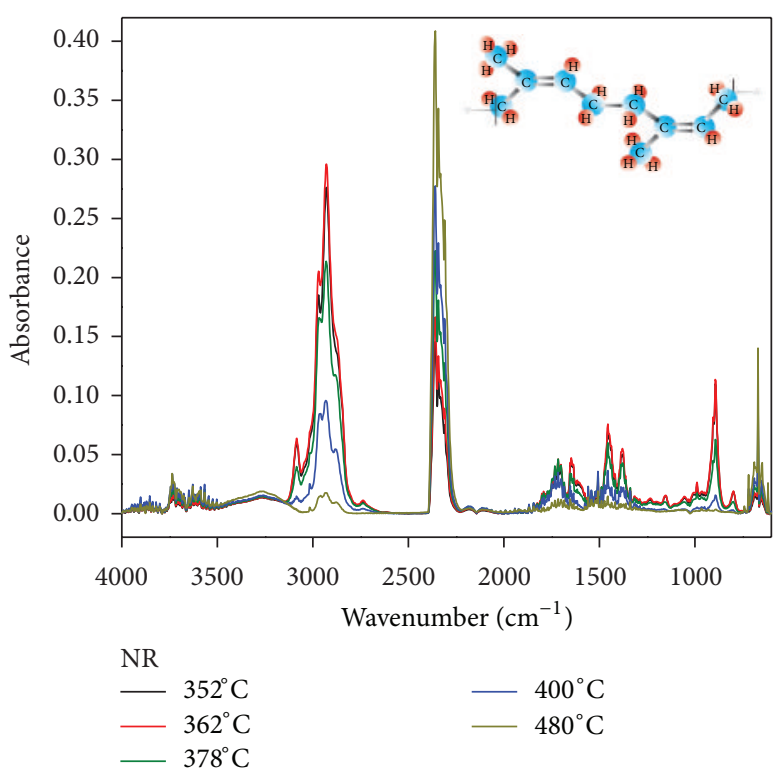

(b)

FIGURE 5: (a) 3D image analysis TG/FT-IR for NR membrane (b) 2D Spectra extracted from the analysis TG/FT-IR for NR membrane at different temperatures of thermal analysis. Representation of natural rubber polymer chain (see inset).

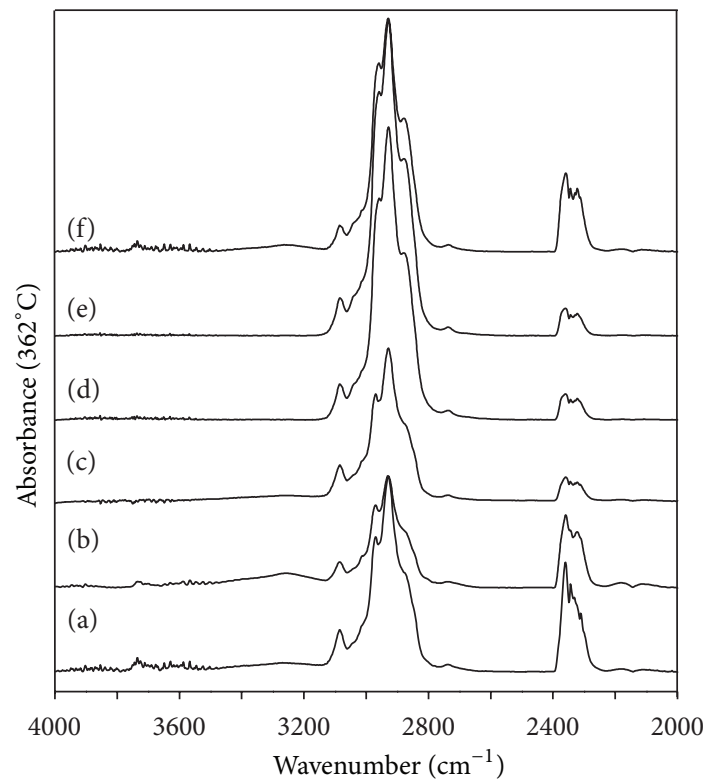

(a)

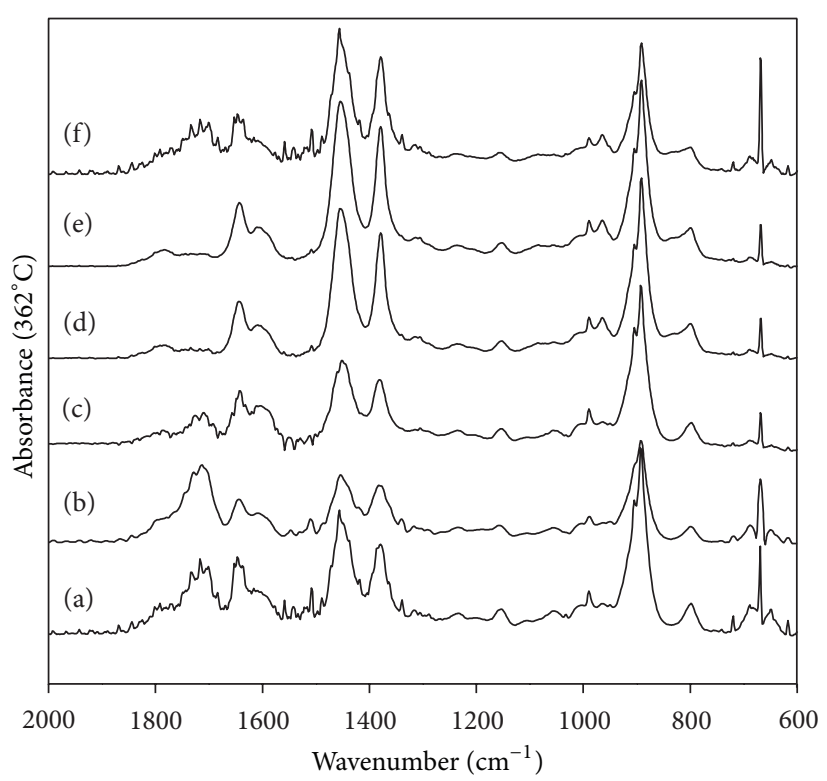

(b)

Figure 6: (I) 2D spectra (2000-4000 $\mathrm{cm}^{-1}$ ) extract analysis TG/FT-IR (temperature $362^{\circ} \mathrm{C}$ ) for pure NR membranes compared to NR/Au membranes prepared at (a) NR; (b) $6 \mathrm{~min}$; (c) $9 \mathrm{~min}$; (d) $15 \mathrm{~min}$; (e) $30 \mathrm{~min}$; and (f) $60 \mathrm{~min}$ reduction times. (II) 2D spectra TG/FT-IR (600$2000 \mathrm{~cm}^{-1}$ ).

degradation and subproducts, like amides, amines, proteins, and carbohydrates, among others. The total characterization and analysis of thermal and mechanical properties has been reported [29]. The spectra extracted from the thermal analysis at different temperatures are shown in Figure 5(b). A comparison between the spectra of natural rubber and those of the NR/Au membranes for different reaction times is given in Figure 6.

The peaks obtained between 2200 and $2400 \mathrm{~cm}^{-1}$ are attributed to the $\mathrm{CO}_{2}$ and $\mathrm{CO}$ molecules released during the thermal analysis. Between 2800 and $3200 \mathrm{~cm}^{-1}$, the compounds relative to $\mathrm{C}-\mathrm{H}$ (isoprene compounds) are observed. 


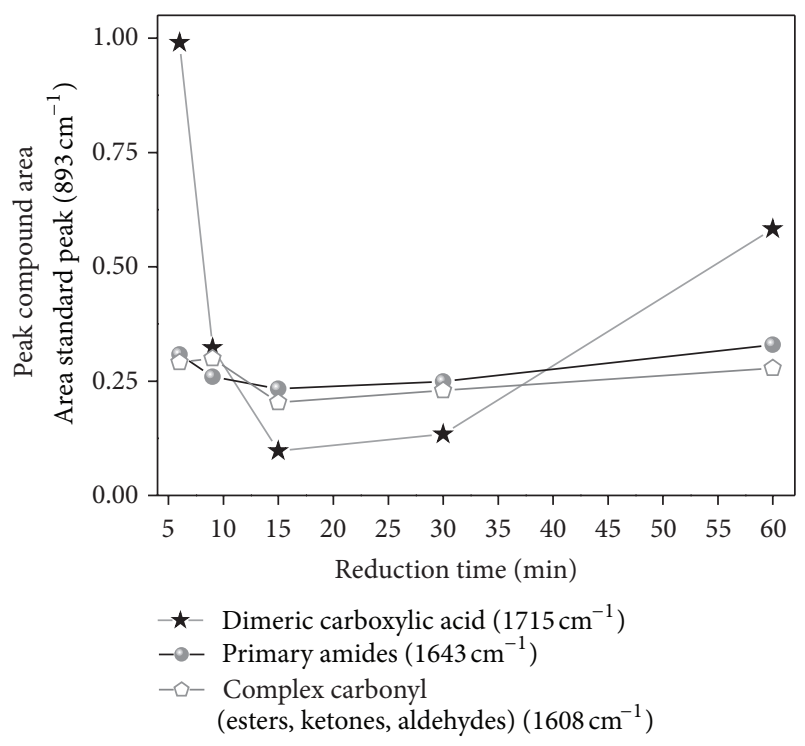

FIgURE 7: Comparison between the areas under the peaks characterized during the TG/FT-IR analysis with respect to the standard peak (relative intensity).

Peaks between 1600 and $1650 \mathrm{~cm}^{-1}$ are attributed to the complex carbonyl (esters, ketones, and aldehydes), proteins and primary amides. The peak in $1715 \mathrm{~cm}^{-1}$ can be attributed to the stretching symmetric $\mathrm{C}=\mathrm{O}$ of carboxylic dimer acid $(-\mathrm{COOH})$. It seems reasonable to postulate that the reducing reagents linked to formation of gold nanoparticles are amides, carboxylic acids, and protein constituents in general.

The comparative analysis between intensity of the peaks attributed to reduction of gold nanoparticles was realized by calculating the relation of the area under lines of these peaks with the area of the standard and distinct peak in spectra maintaining an equal measurement interval of wavenumber (Table S2 supporting information) showed in Figure 7.

Compounds presenting an exponential decrease in quantity relative to increase of the reduction time until 15 minutes, act directly in the synthesis of the nanoparticles proportionally to reduction time. However, for reduction times over 30 minutes, a small increase of these compounds is detected, which may correspond to slower reactions kinetics. The concentration of organic groups, like amide and carboxylic acids groups, leads to increase of the relative intensity evaluated by FT-IR spectroscopy.

3.3. Study of the Gold Nanoparticles Dispersed in Solution. After the evaluation of NR/Au substrates, we analyzed the solution to study the formation of gold nanoparticles relative to a different latex thermal treatment. Figure 8 shows the UV-Vis spectroscopy of solution relative to $120 \mathrm{~min}$ of reduction time comparing the use of natural rubber membranes as reducer agent prepared at 65,80 , and $120^{\circ} \mathrm{C}$ by annealing.

The solution's color changes between 15 and 30 minutes, more intense purple color with the increase of the temperature of preparation of the natural rubber membranes (inset).
TABLE 2: Size measurements from SEM microscopy images of gold nanoparticles prepared in solution (120 min). Synthesis using natural rubber membranes annealed at (a) $65^{\circ} \mathrm{C}$; (b) $80^{\circ} \mathrm{C}$, and (c) $120^{\circ} \mathrm{C}$.

\begin{tabular}{lccc}
\hline \multicolumn{4}{c}{ Statistical function-arbitrary line $(\mathrm{nm})$} \\
Sample & $\begin{array}{c}\mathrm{NR} \\
\left(65^{\circ} \mathrm{C}\right)\end{array}$ & $\begin{array}{c}\mathrm{NR} \\
\left(80^{\circ} \mathrm{C}\right)\end{array}$ & $\begin{array}{c}\mathrm{NR} \\
\left(120^{\circ} \mathrm{C}\right)\end{array}$ \\
\hline Count & 84 & 96 & 280 \\
Mean & 138.20 & 51.25 & 70.11 \\
Minimum & 43.93 & 23.88 & 36.55 \\
Maximum & 433.68 & 88.19 & 158.03 \\
Standard Deviation & 88.49 & 13.36 & 21.53 \\
\hline
\end{tabular}

The bands around $560 \mathrm{~nm}$ are attributed to the LSPR of gold nanoparticles.

Figure 9 presents the SEM microscopy results from gold aqueous solution after the synthesis of nanoparticles at 120 min of reduction time, using natural rubber membranes.

The membranes annealed at $65^{\circ} \mathrm{C}$ showed lowest absorbance due to gold nanoparticle plasmons. The microscopy shows the presence of small circular gold nanoparticles (Figure 9(a)). These results could be explained by the discharge of reducing agents provided by the natural rubber membranes prepared at $65^{\circ} \mathrm{C}$. The amount of nanoparticles increases with the rise of the annealing temperature of membrane fabrication; see, for instance, the results of the synthesis for membranes annealed at $80^{\circ} \mathrm{C}$ (Table 2). The natural rubber membranes annealed at $120^{\circ} \mathrm{C}$ produce larger nanoparticles with a more homogeneous size distribution (Figure 9(c)) that is attributed to greater amount of reducing agents released by the membrane into the solution.

According to this, the best annealing temperature of the natural rubber membranes to prepare gold nanoparticles solution should be between 80 and $120^{\circ} \mathrm{C}$. However, synthesis of gold nanoparticles on the natural rubber surface, for SERS and SERRS substrate active, should be better when natural rubber membranes annealed at $65^{\circ} \mathrm{C}$ are used.

\section{Conclusion}

In this report of a new green chemistry, simple and clean method for in situ synthesis of gold nanoparticles dispersed in solution and on the surface of the flexible substrate is presented. Scanning electron microscopy images show that specific conditions for membrane fabrication can lead to a homogeneous distribution of the nanoparticles on surface of the membranes and colloidal solutions. Managing the reaction time (immersion time) permits to control both the surface coverage and the nanoparticle size. Thermogravimetric analysis coupled with FT-IR spectroscopy and FT-IR/ATR on the membrane surface shows significant variations in the peak assigned to nonrubber components (amines, carboxylic acids) due to gold nanoparticles incorporation, when compared with the spectrum of pure natural rubber membrane, supporting the identification of the components responsible for the gold nanoparticles formation. 

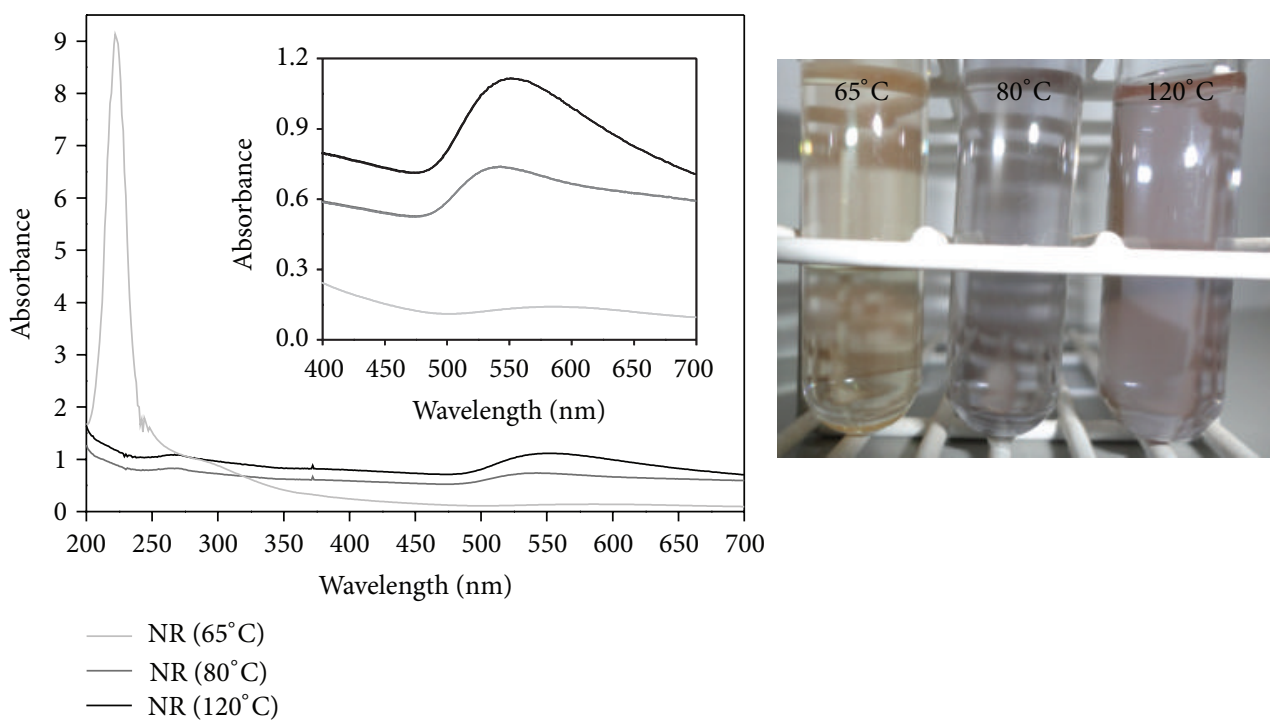

FIGURE 8: UV-Vis spectroscopic analysis of solutions used in the synthesis of gold nanoparticles for 120 min reduction time with natural rubber prepared at 65,80 , and $120^{\circ} \mathrm{C}$ casting temperature.

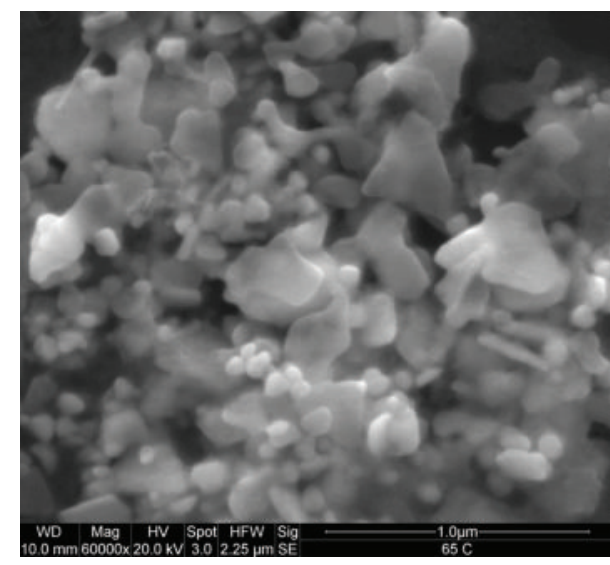

(a)

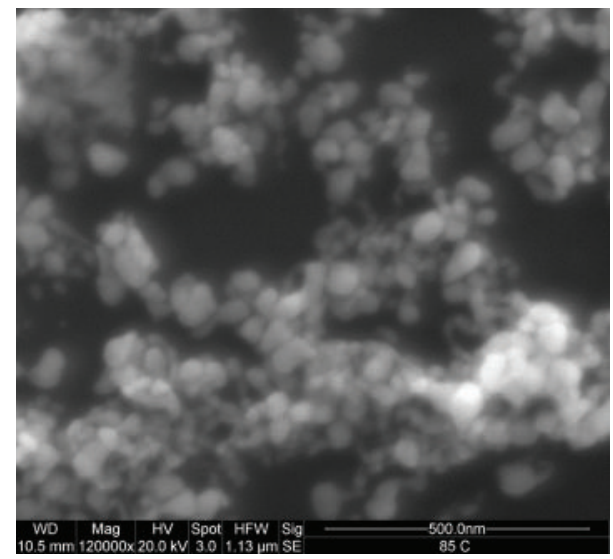

(b)

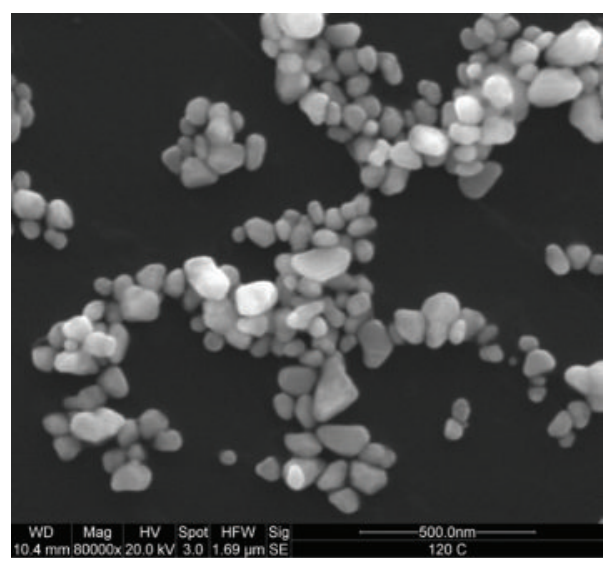

(c)

FIGURE 9: SEM microscopy analysis of solution used in synthesis of gold nanoparticles for 120 min reduction time using natural rubber (reducing agent) annealed at (a) $65^{\circ} \mathrm{C}$, (b) $80^{\circ} \mathrm{C}$, and (c) $120^{\circ} \mathrm{C}$ temperature. The solution is centrifuged to concentrate the amount of nanoparticles before SEM analysis. 


\section{Acknowledgments}

The authors acknowledge the FAPESP, INEO, NanoBioMed, and NanoBioNet groups, for financial support.

\section{References}

[1] M. Rycenga, C. M. Cobley, J. Zeng et al., "Controlling the synthesis and assembly of silver nanostructures for plasmonic applications," Chemical Reviews, vol. 111, no. 6, pp. 3669-3712, 2011.

[2] M. R. Jones, K. D. Osberg, R. J. MacFarlane, M. R. Langille, and C. A. Mirkin, "Templated techniques for the synthesis and assembly of plasmonic nanostructures," Chemical Reviews, vol. 111, no. 6, pp. 3736-3827, 2011.

[3] L. Rivas, S. Sanchez-Cortes, J. V. García-Ramos, and G. Morcillo, "Mixed silver/gold colloids: a study of their formation, morphology, and surface-enhanced raman activity," Langmuir, vol. 16, no. 25, pp. 9722-9728, 2000.

[4] Z. Wang, B. Tan, I. Hussain et al., "Design of polymeric stabilizers for size-controlled synthesis of monodisperse gold nanoparticles in water," Langmuir, vol. 23, no. 2, pp. 885-895, 2007.

[5] Y. N. Xia, Y. J. Xiong, B. Lim, and S. E. Skrabalak, "Shape-controlled synthesis of metal nanocrystals: simple chemistry meets complex physics?" Angewandte Chemie, vol. 48, no. 1, pp. 60103, 2009.

[6] K. L. Kelly, E. Coronado, L. L. Zhao, and G. C. Schatz, "The optical properties of metal nanoparticles: the influence of size, shape, and dielectric environment," Journal of Physical Chemistry B, vol. 107, no. 3, pp. 668-677, 2003.

[7] J. P. Camden, J. A. Dieringer, J. Zhao, and R. P. van Duyne, "Controlled plasmonic nanostructures for surface-enhanced spectroscopy and sensing," Accounts of Chemical Research, vol. 41, no. 12, pp. 1653-1661, 2008.

[8] R. Aroca, Surface-Enhanced Vibrational Spectroscopy, John Wiley \& Sons, Chichester, UK, 2006.

[9] E. C. Le Ru and P. G. Etchegoin, Principles of Surface-Enhanced Raman Spectroscopy: And Related Plasmonic Effects, Elsevier, Amsterdam, The Netherlands, 2009.

[10] R. F. Aroca, R. A. Alvarez-Puebla, N. Pieczonka, S. SanchezCortez, and J. V. Garcia-Ramos, "Surface-enhanced Raman scattering on colloidal nanostructures," Advances in Colloid and Interface Science, vol. 116, no. 1-3, pp. 45-61, 2005.

[11] P. C. Andersen, M. L. Jacobson, and K. L. Rowlen, "Flashy silver nanoparticles," Journal of Physical Chemistry B, vol. 108, no. 7, pp. 2148-2153, 2004.

[12] D.-Y. Wu, J.-F. Li, B. Ren, and Z.-Q. Tian, "Electrochemical surface-enhanced Raman spectroscopy of nanostructures," Chemical Society Reviews, vol. 37, no. 5, pp. 1025-1041, 2008.

[13] B. Ren, G. K. Liu, X. B. Lian, Z. L. Yang, and Z. Q. Tian, "Raman spectroscopy on transition metals," Analytical and Bioanalytical Chemistry, vol. 388, no. 1, pp. 29-45, 2007.

[14] M. J. Banholzer, J. E. Millstone, L. Qin, and C. A. Mirkin, "Rationally designed nanostructures for surface-enhanced Raman spectroscopy," Chemical Society Reviews, vol. 37, no. 5, pp. 885897,2008

[15] A. Annamalai, V. L. P. Christina, D. Sudha, M. Kalpana, and P. T. V. Lakshmi, "Green synthesis, characterization and antimicrobial activity of Au NPs using Euphorbia hirta L. leaf extract," Colloids and Surfaces B, vol. 108, pp. 60-65, 2013.
[16] V. G. Kumar, S. D. Gokavarapu, A. Rajeswari et al., "Facile green synthesis of gold nanoparticles using leaf extract of antidiabetic potent Cassia auriculata," Colloids and Surfaces B, vol. 87, no. 1, pp. 159-163, 2011.

[17] M. V. Sujitha and S. Kannan, "Green synthesis of gold nanoparticles using Citrus fruits (Citrus limon, Citrus reticulata and Citrus sinensis) aqueous extract and its characterization," Spectrochimica Acta A, vol. 102, pp. 15-23, 2013.

[18] G. Gajanan, M. Chang, J. Kim, and E. Jin, "Biogenic materialization using pear extract intended for the synthesis and design of ordered gold nanostructures," Journal of Materials Science, vol. 46, no. 14, pp. 4741-4747, 2011.

[19] S. A. Aromal and D. Philip, "Green synthesis of gold nanoparticles using Trigonella foenum-graecum and its size-dependent catalytic activity," Spectrochimica Acta A, vol. 97, pp. 1-5, 2012.

[20] R. Vijayakumar, V. Devi, K. Adavallan, and D. Saranya, "Green synthesis and characterization of gold nanoparticles using extract of anti-tumor potent Crocus sativus," Physica E, vol. 44, no. 3, pp. 665-671, 2011.

[21] M. Noruzi, D. Zare, K. Khoshnevisan, and D. Davoodi, "Rapid green synthesis of gold nanoparticles using Rosa hybrida petal extract at room temperature," Spectrochimica Acta A, vol. 79, no. 5, pp. 1461-1465, 2011.

[22] D. Parial, H. K. Patra, A. K. R. Dasgupta, and R. Pal, "Screening of different algae for green synthesis of gold nanoparticles," European Journal of Phycology, vol. 47, no. 1, pp. 22-29, 2012.

[23] K. B. Narayanan and N. Sakthivel, "Synthesis and characterization of nano-gold composite using Cylindrocladium floridanum and its heterogeneous catalysis in the degradation of 4nitrophenol," Journal of Hazardous Materials, vol. 189, no. 1-2, pp. 519-525, 2011.

[24] H. Bar, D. K. Bhui, G. P. Sahoo, P. Sarkar, S. Pyne, and A. Misra, "Green synthesis of silver nanoparticles using seed extract of Jatropha curcas," Colloids and Surfaces A, vol. 348, no. 1-3, pp. 212-216, 2009.

[25] H. Bar, D. K. Bhui, G. P. Sahoo et al., "Green synthesis of silver nanoparticles using latex of Jatropha curcas," Colloids and Surfaces A, vol. 339, no. 1-3, pp. 134-139, 2009.

[26] E. J. Guidelli, A. P. Ramos, M. E. D. Zaniquelli, and O. Baffa, "Green synthesis of colloidal silver nanoparticles using natural rubber latex extracted from Hevea brasiliensis," Spectrochimica Acta A, vol. 82, no. 1, pp. 140-145, 2011.

[27] N. H. H. Abu Bakar, J. Ismail, and M. Abu Bakar, "Synthesis and characterization of silver nanoparticles in natural rubber," Materials Chemistry and Physics, vol. 104, no. 2-3, pp. 276-283, 2007.

[28] M. Abu Bakar, J. Ismail, C. H. Teoh, W. L. Tan, and S. Ong, "Epoxidised natural rubber-stabilised gold colloids prepared in an organic mixture of toluene and 2-propanol," Journal of Rubber Research, vol. 11, no. 4, pp. 196-208, 2008.

[29] D. L. S. Agostini, C. J. L. Constantino, and A. E. Job, “Thermal degradation of both latex and latex cast films forming membranes," Journal of Thermal Analysis and Calorimetry, vol. 91, no. 3, pp. 703-707, 2008.

[30] M. Ferreira, R. M. B. Moreno, P. S. Gonçalves, and L. H. C. Mattoso, Boletim de Pesquisa, EMBRAPA, São Carlos, Brazil, 1999.

[31] M. M. Rippel, Caracterização Microestrutural de filmes e partículas de látex de borracha natural [Ph.D. thesis], Universidade Estadual de Campinas (UNICAMP) Instituto de Química, 2005. 
[32] N. V. David, X. L. Gao, and J. Q. Zheng, "Stress relaxation of a twaron/natural rubber composite," Journal of Engineering Materials and Technology, vol. 133, no. 1, Article ID 011001, 9 pages, 2011.

[33] S. Fatima and A. R. Mohanty, "Acoustical and fire-retardant properties of jute composite materials," Applied Acoustics, vol. 72, no. 2-3, pp. 108-114, 2011.

[34] A. J. Keslarek, C. A. P. Leite, and F. Galembeck, "Surfactant and counter-ion distribution in styrene-butyl acrylate-acrylic acid dry latex submonolayers," Journal of the Brazilian Chemical Society, vol. 15, no. 1, pp. 66-74, 2004.

[35] I. B. Cursi, M. A. Cipriani Frade, F. Fortes Andrade et al., "Management of diabetic skin wounds with a natural latex biomembrane," Medicina Cutanea Ibero-Latino-Americana, vol. 32, no. 4, pp. 157-162, 2004.

[36] F. C. Cabrera, P. H. B. Aoki, R. F. Aroca, C. J. L. Constantino, D. S. dos Santos, and A. E. Job, "Portable smart films for ultrasensitive detection and chemical analysis using SERS and SERRS," Journal of Raman Spectroscopy, vol. 43, no. 4, pp. 474-477, 2012.

[37] C. G. Barboza, F. C. Cabrera, R. J. dos Santos, J. A. D. Saez, and A. E. Job, "The influence of natural rubber/Au nanoparticle membranes on the physiology of Leishmania brasiliensis," Experimental Parasitology, vol. 130, no. 2, pp. 152-158, 2012.

[38] M. I. T. de Souza, J. Q. Silva, P. D. S. Gonçalves et al., "Rubber tree exploitation systems utilized in Asian clones Prang Besar, in the West of São Paulo, Brazil," Pesquisa Agropecuaria Brasileira, vol. 42, no. 7, pp. 949-955, 2007.

[39] F. C. Cabrera, D. L. S. Agostini, R. J. dos Santos, S. R. Teixeira, M. A. Rodriguez-Perez, and A. E. Job, "Characterization of natural rubber/gold nanoparticles SERS-active substrate," Journal Applied Polymer Science, vol. 130, no. 1, pp. 186-192, 2013.

[40] A. M. Healey, P. J. Hendra, and Y. D. West, "A fourier-transform Raman study of the strain-induced crystallization and cold crystallization of natural rubber," Polymer, vol. 37, no. 18, pp. 4009-4024, 1996.

[41] P. Nallasamy and S. Mohan, "Vibrational spectra of cis-1,4polyisoprene," The Arabian Journal for Science and Engineering, vol. 29, no. 1, pp. 17-26, 2004.

[42] M. A. de Paoli, Degradação e Estabilização de Polímeros, ChemKeys, 2nd edition, 2008.

[43] M. R. Slabaugh and S. L. Seager, Organic and Biochemistry for Today, 4th edition, 1999.

[44] S. Amnuaypornsri, J. Sakdapipanich, and Y. Tanaka, "Highly purified natural rubber by saponificaion of latex: analysis of green and cured properties," Journal of Applied Polymer Science, vol. 118, no. 6, pp. 3524-3531, 2010. 

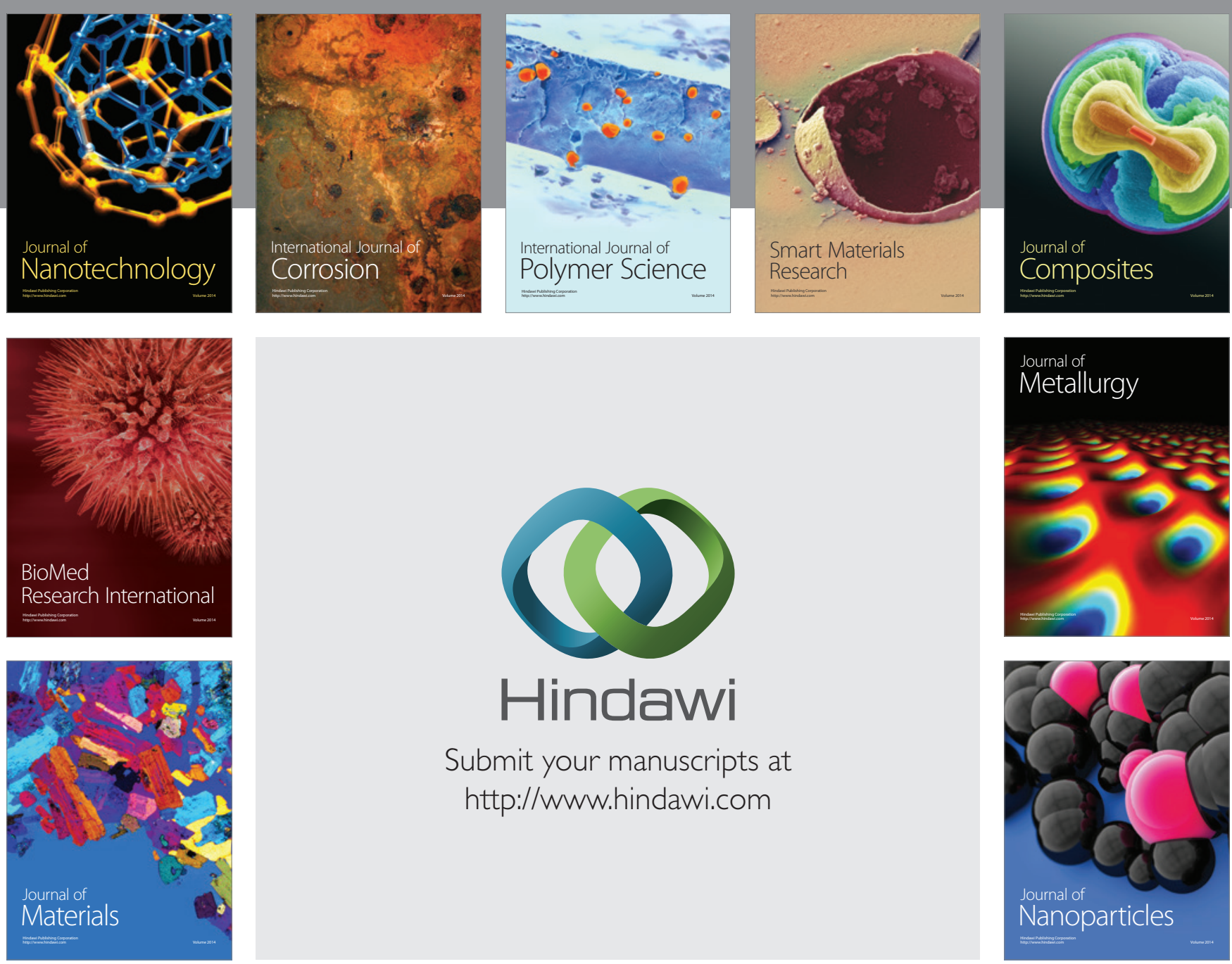

Submit your manuscripts at http://www.hindawi.com
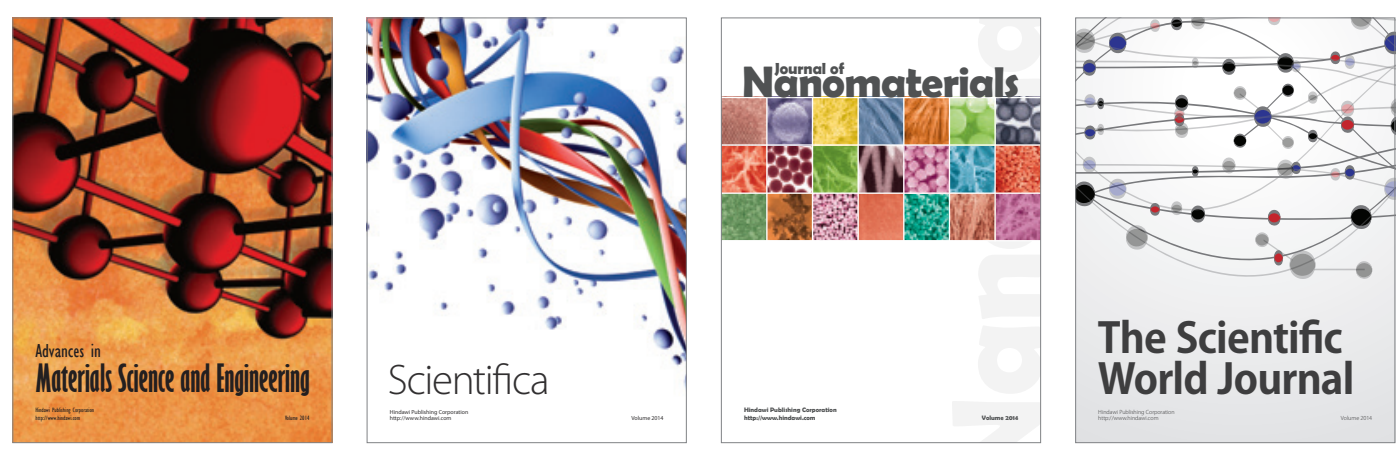

\section{The Scientific World Journal}
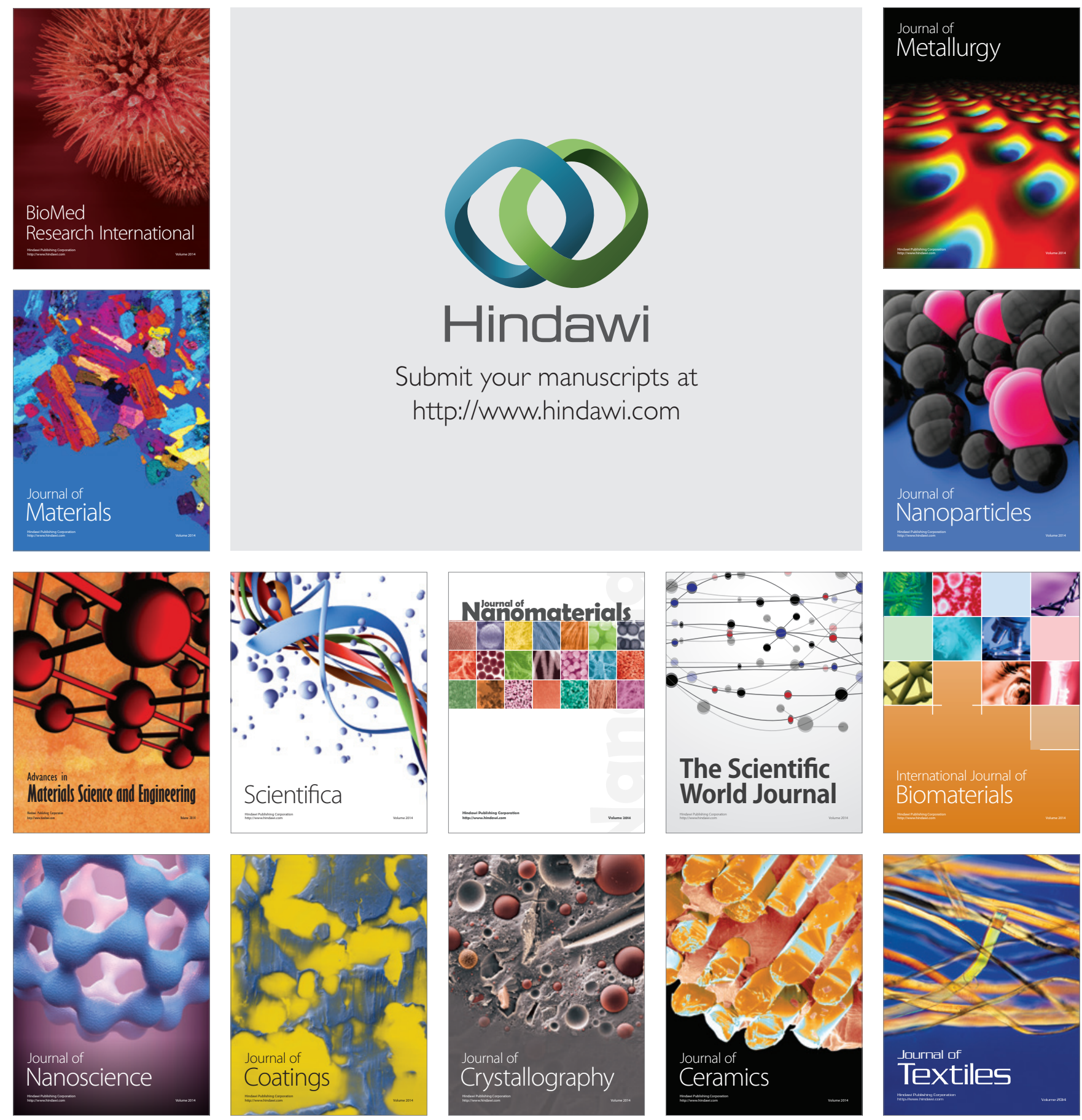